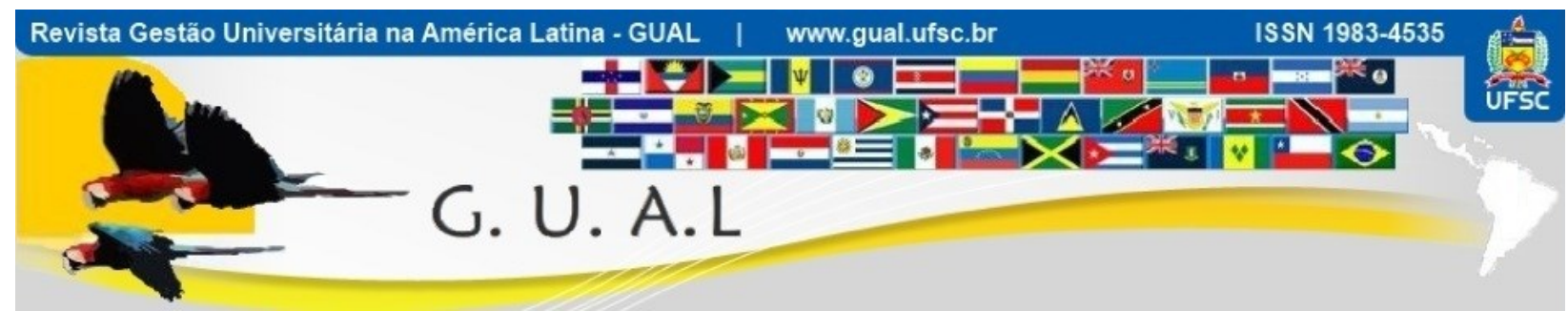

DOI: http://dx.doi.org/10.5007/1983-4535.2015v8n3p70

\title{
DETERMINAÇÃO DO CÁLCULO DO CUSTO POR VAGA E MATRÍCULA EFETIVA EM UNIVERSIDADE PÚBLICA
}

\author{
DETERMINATION OF THE CALCULATION OF COST PER SEAT AND \\ EFFECTIVE ENROLLMENT IN PUBLIC UNIVERSITY
}

\author{
Aline Cristina da Silva Heusi, Mestre \\ Universidade do Estado de Santa Catarina - UDESC \\ alinecsilva9@hotmail.com \\ Mário César Barreto Moraes, Doutor \\ Universidade do Estado de Santa Catarina - UDESC \\ mcbmstrategos@gmail.com \\ Fabiano Maury Raupp, Doutor \\ Universidade do Estado de Santa Catarina - UDESC \\ fabianoraupp@hotmail.com \\ Ilse Maria Beuren, Doutora \\ Universidade Federal de Santa Catariana - UFSC \\ jlklein@uol.com.br
}

Recebido em 25/janeiro/2014

Aprovado em 23/junho/2015

Sistema de Avaliação: Double Blind Review

Esta obra está sob uma Licença Creative Commons Atribuição-Uso. 


\title{
RESUMO
}

O objetivo deste artigo é apresentar os resultados correspondentes à determinação do cálculo de custo por vaga e matrícula efetiva em uma Universidade Pública, especificamente, no Centro de Artes da Universidade do Estado de Santa Catarina. A adoção de sistemas de custos pelas organizações públicas é relevante por diversas razões, como: previsão legal, auxílio na tomada de decisões, análise de produtividade, eficiência e eficácia, priorização de políticas públicas, entre outras. Trata-se de uma pesquisa descritiva e interpretativa, realizada por meio de um estudo de caso, com abordagem qualitativa e quantitativa. A coleta de dados foi realizada por meio de relatórios gerenciais, relatórios de sistemas e entrevistas informais. A análise dos dados, realizada por meio de técnicas descritiva e interpretativa, aponta que o custo por vaga de graduação, neste estudo de caso, importou em uma média de R\$ 23.200,72/ano e o custo médio de matrícula efetiva em R\$19.679,25/ano na graduação. O custo por vaga de Pós-Graduação importou em uma média de R \$ 35.528,99/ano e o custo médio de cada matrícula efetiva em $\mathrm{R} \$ 43.714,25 / \mathrm{ano}$.

Palavras-chave: Custo por vaga. Custo por matrícula efetiva. Universidade Pública.

\begin{abstract}
The purpose of this article is to present the results for the determination of the estimate cost per seat and effective enrollment in a public university, specifically, at the Arts Center of the University of the State of Santa Catarina. The adoption of cost systems by public organizations is relevant for several reasons, such as: legal provision, aid in decision making, productivity analysis, efficiency and effectiveness, prioritization of public policies, among others. This is a descriptive and interpretative research, carried out through a case study with a qualitative and quantitative approach. Data collection was performed by means of management reports, system reports and informal interviews. Data analysis, performed by descriptive and interpretive techniques, points out that the cost per seat of undergraduate education, in this case study, imported at an average of $\mathrm{R} \$ 23,200.72 /$ year and the average cost of effective enrollment in R \$ 19,679.25/year of undergraduation. The cost per graduate seat imported at an average of $\mathrm{R} \$ 35,528.99 /$ year and the average cost of each effective enrollment at $\mathrm{R} \$ 43,714.25 /$ year.
\end{abstract}

Keywords: Cost per job. Cost per enrollment effective. Public University. 


\section{INTRODUÇÃO}

A utilização de sistemas de custos em órgãos públicos, no Brasil, ainda se demonstra incipiente, existindo, portanto, amplo espaço ao seu desenvolvimento e implantação. A pesquisa realizada por Heusi, Raupp e Moraes (2014) evidencia que as universidades públicas federais e estaduais brasileiras não estão utilizando um sistema de custo. De 74 questionários enviados às Universidades delimitadas como objeto do estudo, obteve-se o retorno de 15 questionários respondidos, representando $20,27 \%$ da população; e, destes questionários, $100 \%$ das Universidades responderam não utilizar um sistema de custos.

O problema do cálculo de custos associados à gestão de uma instituição pública ganha relevância quando do processo de tomada de decisão numa Instituição de Ensino Superior, destacando-se como indispensável à correta consecução do orçamento. Neste sentido, a apropriada determinação dos custos inerentes ao processo de ensino, pesquisa e extensão, em uma instituição pública, é revestida de importância ainda maior quando considerada a responsabilidade social.

Magalhães (2010, p. 21) aduz que, "tendo em vista o valor da educação para o desenvolvimento e considerando que o recurso aplicado neste setor é limitado, a alocação eficiente deste recurso é fundamental à manutenção do nível qualitativo do ensino ofertado à sociedade brasileira". Para isto, é necessária a adoção de sistemas de custos, a fim de produzir informações que auxiliem a administração a medir os resultados e a avaliar o patrimônio (LEONE, 2009).

Diante desse contexto, neste estudo pretende-se responder a seguinte pergunta de pesquisa: Como se determina o cálculo de custo por vaga e matrícula efetiva de graduação e pós-graduação em um Centro de uma Universidade Pública pela metodologia de custeio por absorção? Assim, o objetivo do estudo é apresentar os resultados correspondentes à determinação do cálculo de custo por vaga e matrícula efetiva em uma Universidade Pública, especificamente, no Centro de Artes da Universidade do Estado de Santa Catarina.

O artigo está organizado em cinco seções, iniciando com esta introdução. Em seguida, é apresentada uma breve incursão teórica, que aborda as classificações dos custos, as metodologias de custeio e os custos no setor público. Na sequência, descreve a metodologia da pesquisa, a descrição e análise dos dados e as conclusões ao estudo realizado. 


\section{FUNDAMENTOS TEÓRICOS}

\subsection{CLASSIFICAÇÃO DOS CUSTOS}

Devido à sua característica e seu tipo, os custos podem ser classificados em custos diretos, indiretos, fixos e variáveis. Para possibilitar a implantação da gestão de custos, seja na área pública ou na privada, é necessária a classificação destes custos.

\subsubsection{Custo Direto}

De acordo com Martins (2008, p. 48), os custos diretos "podem ser diretamente apropriados aos produtos, bastando haver uma medida de consumo (quilograma de materiais consumidos, embalagens utilizadas, horas de mão-de-obra usada e até quantidade de força consumida)". Maher (2001, p. 69) conceitua custo direto como "qualquer custo que pode ser relacionado diretamente com um objeto do custo". Mauss e Souza (2008, p. 24) corroboram com Maher e definem custo direto como "todo o custo que é identificado naturalmente ao objeto do custeio".

Assim, custos diretos são custos de fácil identificação e apropriados diretamente ao produto. Alguns exemplos de custos diretos são: matéria-prima, mão de obra da produção; depreciação e manutenção de máquinas e equipamentos da produção.

\subsubsection{Custo Indireto}

Os custos indiretos, segundo Martins (2008, p. 49), "não oferecem condição de uma medida objetiva, e qualquer tentativa de alocação tem de ser feita de maneira estimada e muitas vezes arbitrária (como o aluguel, a supervisão, as chefias, etc.)”. Para Mauss e Souza (2008, p. 24), o custo indireto "não oferece identificação direta a um objeto de custeio, necessita de esquemas especiais para a alocação, como bases de rateio ou direcionadores".

Maher (2001, p. 69) classifica como custo indireto "qualquer custo que não pode ser relacionado diretamente com um objeto do custo". Exemplifica-se como custo indireto os salários do pessoal administrativo, a depreciação e manutenção dos equipamentos administrativos numa indústria.

\subsubsection{Custo Fixo}

Martins e Rocha (2010, p. 22) conceituam que "custos fixos são aqueles cujo montante não é afetado pelo volume, dentro de determinado intervalo do nível de atividade". Maher 
(2001 p. 75) também define custos fixos como sendo aqueles "custos que não se alteram quando o volume se altera, dentro de um intervalo relevante de atividade".

De acordo com Mauss e Souza (2008, p. 24), o custo fixo "é o que não leva em consideração as oscilações de produção, tendo, portanto, o seu valor constante no intervalo relevante de atividades". Exemplifica-se como custos fixos: seguro de edifícios, vigilância patrimonial, salário e encargos sociais do pessoal da portaria.

\subsubsection{Custo Variável}

Segundo Mauss e Souza (2008, p. 24), o custo variável "tem seu valor determinado e diretamente relacionado com a oscilação na produção e execução dos serviços". Martins e Rocha (2010, p. 25) definem que "custos variáveis são aqueles cujo montante é afetado de maneira direta pelo volume, dentro de determinado intervalo do nível de atividade".

Ao contrário dos custos indiretos e diretos, os quais são caracterizados pela dificuldade ou facilidade de alocação, os custos variáveis são caracterizados pela proporcionalidade ao volume de produção, ou seja, o incremento se verifica, proporcionalmente, à quantidade produzida ou de serviço prestado. Alguns exemplos de custos variáveis podem ser citados: matéria-prima da produção, material de embalagem, mão de obra da produção (se for contratada por volume produzido).

\subsubsection{Despesa}

Segundo Martins (2008, p. 25), despesa é o "bem ou serviço consumido direta ou indiretamente para a obtenção de receitas”. Para Cruz e Platt Neto (2007, p. 38-39), despesa "é o gasto cuja expressão física, na forma de bem ou serviço, não é utilizada na transformação e produção do produto final”.

Para Martins e Rocha (2010, p. 17), a “despesa está relacionada ao processo de geração de receita; o termo custo refere-se ao momento em que os recursos estão sendo utilizados, consumidos ou transformados; e despesa é o vocábulo contábil que designa os valores confrontados com a receita no momento ou no período da sua realização".

Pode-se exemplificar despesas na área de administração como: a energia elétrica consumida pelas máquinas e equipamentos da administração geral e a sua depreciação; e o seguro de máquinas, dos equipamentos, das instalações e dos edifícios da administração. 


\subsection{METODOLOGIAS DE CUSTEIO}

Nakagawa (2009, p. 54) afirma que "cada método de custeio tem sua área própria e específica de eficácia, ou seja, um não substitui o outro, apenas se complementam”. Bonacim e Araujo (2010, p. 909) corroboram com a afirmação de Nakagawa e complementam que: "é possível a adoção simultânea e harmoniosa das alternativas, visto que não são excludentes entre si, cada qual com um conjunto de informações específicas às funções de controle e planejamento das atividades de uma entidade".

\subsubsection{Custeio por Absorção}

Custeio por Absorção, segundo Martins (2008, p. 37), “consiste na apropriação de todos os custos de produção aos bens elaborados, e só os de produção; todos os gastos relativos ao esforço de produção são distribuídos para todos os produtos ou serviços feitos". Maher (2001, p. 360) define Custeio por Absorção como "sistema de contabilização de custos, no qual tanto os custos fixos como os variáveis de produção são considerados custos do produto", ou seja, "pressupõe que os produtos absorvam todos os custos de produção".

No Custeio por Absorção, os custos são atribuídos aos produtos por meio de centros de custos. Os centros de custos de produção, segundo Martins e Rocha (2010, p.88), "são aqueles nos quais os recursos são utilizados para realizar atividades que incidem diretamente sobre materiais e equipamentos, convertendo-os em produtos - bens ou serviços - destinados a clientes externos".

Para fins de implantação de um sistema de custos inicial, o custeio por absorção é menos complexo que o $\mathrm{ABC}$, exigindo menos investimentos financeiros e menos recursos humanos para sua implantação, e seu benefício para a organização poderá ser aplicado imediatamente no planejamento orçamentário, nas tomadas de decisões, no estabelecimento de metas e prioridades, na identificação à otimização de recursos, entre outras.

\subsubsection{Custeio Variável}

Custeio Variável, conforme Maher (2001, p. 360), é o "sistema de contabilização de custos em que apenas os custos variáveis de produção são atribuídos aos produtos”, ou seja, "os custos fixos de produção são considerados despesa do período". O método de Custeio Variável, segundo Martins e Rocha (2010, p. 65), “considera como sendo dos produtos exclusivamente seus custos variáveis, somente eles. Todos os custos fixos, inclusive os 
identificáveis com os produtos (custos fixos diretos), são debitados ao resultado do período em que são incorridos".

O valor do resultado individual de cada produto pode ser calculado, através da dedução da receita líquida do produto, os custos e despesas variáveis totais do produto, que resultará na Margem de Contribuição. Essa margem mostra a contribuição de cada produto para a cobertura dos custos e despesas fixas da empresa (MARTINS; ROCHA, 2010).

Mauss e Souza (2008) recomendam a utilização do custeio variável na gestão pública, por possibilitar uma visão mais global e objetiva dos custos dos serviços prestados. Porém, o método de custeio variável não é aceito pelo Fisco. Por isso, esse método não é reconhecido pelos contadores na avaliação de estoque e não admitem seu uso nas Demonstrações de Resultados e Balanços, pois o custeio variável fere os Princípios Contábeis.

\subsubsection{Custeio Baseado em Atividades (Activity Based Costing - ABC)}

Nakagawa (2009, p. 39-40) conceitua ABC como uma "metodologia desenvolvida para facilitar a análise estratégica de custos relacionados com as atividades que mais impactam o consumo de recursos de uma empresa". No $\mathrm{ABC}$, "os recursos de uma empresa são consumidos por suas atividades e não pelos produtos que ela fabrica".

Para Maher (2001, p. 280), “o custeio baseado em atividades é um método de custeio em que os custos, inicialmente, são atribuídos às atividades e depois aos produtos, com base no consumo de atividades pelos produtos". Neste método, os "produtos consomem atividades e atividades consomem recursos".

Martins e Rocha (2010, p. 142-143) descrevem a atividade como "uma ação em que se utilizam materiais e humanos (input), associados à determinada tecnologia, para gerar bens ou serviços (output)". Esses autores consideram a primeira etapa do ABC a "identificação dos processos relevantes e, a partir da análise de cada um, as atividades são identificadas em suas respectivas unidades organizacionais (departamentos, etc.)".

De acordo com Martins (2008, p. 96), o direcionador de custos "deve ser o fator que determina ou influencia a maneira como os produtos consomem (utilizam) as atividades". Cada atividade poderá ter um direcionador de custo diferente, que será obtida através de estudos e pesquisas. Alguns exemplos de direcionadores de custos são: horas-máquinas, horas de mão de obra, pedidos de compra, quantidade de itens produzidos ou vendidos, quantidade de clientes atendidos, horas de voo e quantidade de cirurgias. 
Porém, o custeio baseado em atividades não é aceito pela legislação brasileira para fins de apuração do custo dos produtos, na dedução da receita para cálculo do imposto nas organizações privadas. Além disso, é um método mais complexo, que exige dedicação e investimento na sua implantação e funcionamento.

\subsection{CUSTOS NO SETOR PÚBLICO}

Os custos também merecem atenção especial no setor público, pois além de estarem previstos na legislação brasileira, a instituição que os adotar poderá referendá-los em seu processo decisório, utilizá-los para avaliação de resultados e desempenhos, entre outros benefícios. Nessa visão, Ribeiro Filho (2012, p. 2-3) aduz que:

(...) na medida em que se supera a fase da administração pública burocrática, sob os embates em torno do Estado mínimo ou máximo e da crise de financiamento para atender demandas sociais crescentes, (re)surgem os conceitos de usuários/clientes, eficácia, eficiência, efetividade, custos e avaliação de resultados e desempenhos, agora aplicados no âmbito das entidades da administração pública.

A Lei Complementar $\mathrm{n}^{\circ}$ 101, de 04 de maio de 2000, a chamada Lei de Responsabilidade Fiscal, prevê no parágrafo $3^{\circ}$ do art. 50, que "a Administração Pública manterá sistema de custos que permita a avaliação e o acompanhamento da gestão orçamentária, financeira e patrimonial".

A Resolução no ${ }^{\circ}$ 1.129/08 do Conselho Federal de Contabilidade, de 21 de novembro de 2008, aprova a Norma Brasileira de Contabilidade NBC T 16.2, que dispõe sobre as diretrizes a serem observadas no setor público quanto aos procedimentos, práticas, elaboração e divulgação das demonstrações contábeis, de forma a torná-las convergentes com as Normas Internacionais de Contabilidade Aplicadas ao Setor Público. Nesta norma está previsto que o sistema de custo é um subsistema de informação do sistema contábil e, nele, será registrado, processado e evidenciado os custos dos bens e serviços, produzidos e ofertados à sociedade pela entidade pública.

A International Public Sector Accounting Standards, que dispõe sobre as normas internacionais de contabilidade aplicadas ao setor público, menciona na IPSAS 1 que "as despesas devem ser subclassificadas, a fim de destacar os custos e as apropriações de custos de programas específicos, atividades ou outros segmentos relevantes à entidade que será retratada pelas demonstrações contábeis" (IPSAS, 2010). O Conselho Federal de Contabilidade, na Resolução ${ }^{\circ}$ 1.366, de 25 de novembro de 2011, aprova pela NBC T 16.11 
o Sistema de Informação de Custos do Setor Público (SICSP), que estabelece a conceituação, o objeto, os objetivos e as regras básicas para mensuração e evidenciação dos custos no setor público e menciona sua obrigatoriedade em todas as entidades do setor público.

Silva (2007, p. 3) afirma que "a produção de informações para o planejamento é um fator importante a ser considerado na implantação da Contabilidade de Custos" e complementa que é necessária "para o entendimento integral do processo e das etapas interrelacionadas, que se iniciam com a definição de objetivos e terminam com a alocação dos recursos para que as metas estabelecidas sejam alcançadas".

Slomski (2006) defende a apuração de custos na administração pública devido à necessidade dos gestores em conhecer os custos de suas entidades, com o intuito de poderem tomar as melhores decisões, escolhendo entre produzir ou comprar produtos e serviços, produzir ou terceirizar e/ou privatizar serviço.

\section{PROCEDIMENTOS METODOLÓGICOS}

Esta pesquisa foi desenvolvida a partir de uma metodologia qualitativa e quantitativa. Para Raupp e Beuren (2004, p. 92), "na pesquisa qualitativa concebem-se análises mais profundas em relação ao fenômeno que está sendo estudado", enquanto que a abordagem quantitativa "caracteriza-se pelo emprego de instrumentos estatísticos, tanto na coleta quanto no tratamento dos dados".

A coleta de dados foi realizada por meio pesquisa documental. Silva (2003, p. 61) caracteriza a pesquisa documental “(...) por utilizar material que ainda não recebeu tratamento analítico ou que pode ser reelaborado; suas fontes são muito mais diversificadas e dispersas". Utilizaram-se na pesquisa documental os relatórios gerados do Sistema de Gerenciamento Orçamentário e Financeiro da UDESC (SIGEOF), relatórios do Sistema de Gerenciamento de Recursos Humanos do Estado (SIGRH) e planilhas gerenciais dos setores de Recursos Humanos, Coordenadoria de Finanças e Contas e Secretarias de Ensino de Graduação e de Pós-Graduação do Centro de Ensino estudado. As entrevistas informais foram realizadas à medida que dúvidas surgiam na interpretação dos relatórios e planilhas gerenciais.

A análise dos dados, segundo Porton e Beuren (2004, p. 136), "significa trabalhar com todo o material obtido durante o processo de investigação”. Já na fase de interpretação dos dados, “(...) deverá haver uma correlação dos dados coletados com a base teórica que sustentou a pesquisa". Assim, para a descrição e interpretação dos dados foi utilizado o 
método de Custeio por Absorção, referenciado na fundamentação teórica, por ser um método inicial na implantação de um sistema de custo, tendo em vista que a Universidade, objeto de estudo, não possui um sistema implantado. Possivelmente o método $\mathrm{ABC}$ será uma etapa futura a ser implementada pela Universidade. Com a implantação do Custeio por Absorção será possível auxiliar no planejamento operacional de médio e longo prazo, mensurar a eficiência e o processo, gestão da capacidade da Universidade para crescimento horizontal e vertical e assessorar a prestação de contas à sociedade.

Os rateios foram realizados de acordo com os indicadores para possibilitar a implementação da proposta de cálculo do custo da vaga do aluno. Assim, os principais rateios realizados com os custos da Reitoria foram o rateio da folha de pagamento e o do custeio de 2013, utilizando como indicador o número total de servidores no Centro de Ensino.

No Centro de Artes, fez-se necessário identificar os docentes e técnicos em cada Departamento, para alocação dos custos diretos com pessoal por centro de custo. A folha de pagamento das Direções Geral e Administrativa foi rateada, utilizando-se como indicador a distribuição igual para todos os departamentos. Nas Direções de Pesquisa e Extensão, o indicador utilizado foi o da quantidade de professores efetivos no departamento. Na Direção de Ensino, foi utilizada a quantidade de vagas de graduação por departamento. Os custos diretos (material de consumo, serviços de terceiros de pessoa jurídica e pessoa física, passagens e diárias) foram colhidas das planilhas gerenciais de cada centro de custo. Os gastos de manutenção administrativa foram rateados, posteriormente, de acordo com cada indicador da despesa.

\section{APRESENTAÇÃO DOS RESULTADOS DO ESTUDO DE CASO}

Instituída pelo Decreto $\mathrm{n}^{\mathrm{o}} 2.802$, em 20 de maio de 1965, a Universidade para o Desenvolvimento do Estado de Santa Catarina - UDESC incorporou as unidades até então existentes em Florianópolis, SC: a Faculdade de Engenharia (criada em 1956), a Faculdade de Educação (criada em 1963) e a Escola Superior de Administração e Gerência (criada em 1964). A Escola Superior de Medicina Veterinária, em Lages, teve seu funcionamento autorizado em 1973. Neste mesmo ano, em Florianópolis foi criada a Escola Superior de Educação Física. O Centro de Artes entrou em funcionamento em 1985, incorporando o Curso de Educação Artística, até então oferecido pela Faculdade de Educação. 
O ensino de Artes nas escolas se tornou obrigatório em 1971, e a Universidade do Estado de Santa Catarina foi solicitada a suprir esta necessidade educacional do mercado de trabalho. Assim, em 1972, a UDESC passou a oferecer Cursos Complementares para professores e, em 1974, lançou vagas no primeiro Vestibular para o Curso de Educação Artística da Universidade. Na época, o Curso oferecia um Núcleo Comum (com a duração de três semestres) e Habilitações (mais três semestres) em Música, Artes Plásticas e Desenho. Em 1985, a UDESC foi reconhecida como Universidade e a criação da habilitação em Artes Cênicas possibilitou tornar o Curso num Centro (o Centro de Artes - CEART).

Atualmente, os cursos de graduação (Artes Cênicas, Artes Visuais, Design, Moda e Música) são independentes e o Centro de Artes tem cursos de pós-graduação em Artes Cênicas (mestrado e doutorado), Música (mestrado), Artes Visuais (mestrado e doutorado) e Design (mestrado), sendo todos reconhecidos pela CAPES (Coordenação de Aperfeiçoamento de Pessoal de Nível Superior). O CEART conta com 1.000 alunos, em média, e oferece grande infraestrutura, com diversos prédios distribuídos em aproximadamente $11 \mathrm{mil} \mathrm{m}^{2} \mathrm{de}$ área construída. A produção acadêmica é relevante e, em seu corpo docente, o CEART conta com 93 docentes efetivos, sendo 64 doutores, 22 mestres e 7 especialistas e 39 docentes substitutos, sendo 4 doutores, 27 mestres, 3 especialistas e 5 graduados e, ainda, 2 professores doutores visitantes. No ano de 2013, o número de vagas oferecidas e o número de alunos matriculados, em cada curso de graduação, estão demonstrados na Tabela 1.

A implantação operacional das diretrizes da "Política Institucional de Pós-Graduação" pela Universidade culminou em diversas ações que possibilitaram ao término de 2012, a UDESC de obter posição de destaque em nível estadual e nacional, com 28 cursos de pósgraduação credenciados. Apenas no Centro de Artes há seis destes cursos, a saber: Mestrado Acadêmico em Design Industrial (2011); Mestrado Acadêmico em Teatro (2002); Doutorado em Teatro (2008); Mestrado Acadêmico em Artes Visuais (2005); Mestrado Acadêmico em Música (2007) e Doutorado em Artes Visuais (2012). 
Tabela 1 Vagas Oferecidas e Matrículas Efetivas por Curso

\begin{tabular}{|c|c|c|c|c|}
\hline \multirow[t]{2}{*}{ Curso } & \multicolumn{2}{|c|}{$\begin{array}{c}\text { Alunos } \\
\text { matriculados } \\
\end{array}$} & \multirow{2}{*}{$\begin{array}{c}\text { Vagas } \\
\text { Curso em } \\
2013.1 \\
\end{array}$} & \multirow{2}{*}{$\begin{array}{c}\text { Vagas } \\
\text { Curso em } \\
2013.2 \\
\end{array}$} \\
\hline & 2013.1 & 2013.2 & & \\
\hline Artes visuais - bacharelado & 133 & 117 & 112 & 112 \\
\hline Artes visuais - licenciatura & 90 & 81 & 80 & 80 \\
\hline Artes Plásticas & 13 & 5 & 0 & 0 \\
\hline Educação Artística - Artes Plástica & 4 & 3 & 0 & 0 \\
\hline Total DAV & 240 & 206 & 192 & 192 \\
\hline Design Gráfico & 94 & 91 & 80 & 80 \\
\hline Design Industrial & 95 & 79 & 80 & 80 \\
\hline Total Design & 189 & 170 & 160 & 160 \\
\hline Educação Artística - Artes Cênicas & 1 & 0 & 0 & 0 \\
\hline Teatro - Licenciatura/Bacharelado & 95 & 86 & 0 & 0 \\
\hline Teatro - Licenciatura & 79 & 74 & 135 & 135 \\
\hline Total DAC & 175 & 160 & 135 & 135 \\
\hline Moda - Design Moda & 201 & 197 & 190 & 190 \\
\hline Moda - estilismo & 13 & 5 & 0 & 0 \\
\hline Total Moda & 214 & 202 & 190 & 190 \\
\hline Educação Artística - Música & 0 & 0 & 0 & 0 \\
\hline Música - licenciatura & 145 & 140 & 120 & 120 \\
\hline Música - Piano & 24 & 24 & 28 & 28 \\
\hline Música - Violão & 11 & 9 & 12 & 12 \\
\hline Música - Viola* & 5 & 2 & 8 & 8 \\
\hline Música - Violino* & 13 & 9 & 12 & 12 \\
\hline Música - Violoncelo & 6 & 6 & 8 & 8 \\
\hline Total Música & 204 & 190 & 188 & 188 \\
\hline
\end{tabular}

Fonte: Secretaria de Ensino do Centro de Artes e Relatório de Gestão UDESC, 2013.

A Reitoria da Universidade do Estado de Santa Cataria está localizada no Campus I (Grande Florianópolis). Sua estrutura é composta pelo Gabinete do Reitor, Pró-Reitorias de Ensino, Pesquisa e Pós-graduação, Extensão e Administração; Secretarias de Comunicação, Controle Interno, Tecnologia da Informação e Comunicação, Cooperação Interinstitucional e Internacional e Arte e Cultura para a Infância e Juventude; Coordenadorias de Projetos e Inovação, Vestibulares e Concursos e Avaliação Institucional; Procuradoria Jurídica; Editora Universitária; Biblioteca Universitária e Museu da Escola Catarinense; Secretaria dos Conselhos Superiores; Conselho Comunitário; e os Conselhos Universitários (CONSUNI), de Ensino, Pesquisa e Extensão (CONSEPE), de Administração (CONSAD) e Curador (CONCUR). Todos os Centros de Ensino estão vinculados diretamente ao Gabinete do Reitor. 
A divisão do orçamento da Universidade entre Centros de Ensino e Reitoria, atualmente, não se utiliza de indicadores de resultado, alunos ou vagas para esta divisão. As divisões do orçamento são realizadas com base no orçamento executado no ano anterior, ou seja, de forma subjetiva. A proposta de uma metodologia para o cálculo do custo da vaga e da matrícula efetiva de alunos de graduação e pós-graduação na Universidade poderá contribuir para a tomada de decisões dos gestores, sendo que, atualmente, elas são realizadas com base na experiência e intuição.

Para a metodologia proposta, pesquisou-se o valor da despesa de custeio utilizado na Reitoria no ano de 2013. As despesas de custeio estão relacionadas aos itens básicos de manutenção de uma instituição, tais como pessoal, material de consumo, serviços de terceiros e encargos diversos; enquanto a despesa de capital é a despesa que resulta no acréscimo do patrimônio, ou seja, um investimento. Esta última não foi considerada no presente trabalho, devido à recente implantação da contabilização da despesa com depreciação, a qual ainda não foi finalizada em todos os grupos de material permanente.

A folha anual da Reitoria, no ano de 2013, foi de R\$20.953.990,73. Para o cálculo deste valor, foi pesquisado o salário bruto do mês de outubro de 2013 na Coordenadoria de Recursos Humanos da UDESC e multiplicado pelo índice 13,33, que representa 12 meses acrescidos do $13^{\circ}$ salário e $1 / 3$ de férias. A escolha do mês de outubro se deu por causa da não interferência do $13^{\circ}$ salário e $1 / 3$ de férias e após a atualização do valor referencial de vencimento (VRV) de 2013. Este valor é reajustado, anualmente, na data-base da Universidade.

O rateio deste custeio aos Centros de Ensino foi através do indicador "quantidade de servidores no Centro de Ensino", por considerar que a Reitoria está disponível a todos os Centros de Ensino da Universidade, sendo que a quantidade de servidores de cada Centro de Ensino influencia e reflete o dispêndio de recurso da Reitoria para este Centro. Assim, o Centro de Artes recebeu R $\$ 2.989 .755,15$ para posterior rateio entre seus centros de custos referente à folha da Reitoria no ano de 2013. A quantidade de servidores dos Centros de Ensino de 2013 foi retirada do Relatório de Gestão 2013 Prestando Contas.

A UDESC possui um sistema onde são registradas todas as operações orçamentárias e financeiras da Instituição, sendo tal sistema denominado Sistema Gerencial Orçamentário e Financeiro da UDESC (SIGEOF). Nele foi possível pesquisar os relatórios por Projeto Atividade e Elemento de Despesa da Reitoria. Somando-se todos os relatórios gerados, o 
custeio da Reitoria, no ano de 2013, totalizou $\mathrm{R} \$ 9.567 .945,10$, considerando apenas a fonte de recurso 0100 Receitas Cotas. Esta fonte de recurso se refere ao repasse mensal do Governo do Estado de Santa Catarina à UDESC. O rateio do custeio da Reitoria do ano de 2013 aos Centros de Ensino da UDESC também utilizou como indicador a quantidade de servidores no Centro de Ensino. O Centro de Artes recebeu o valor de R\$ 1.036.952,34 para posterior alocação aos seus centros de custo. Acrescentando o valor recebido da folha de pagamento da Reitoria, o Centro de Artes recebeu o montante de R 3.376.059,43 para alocação no custo das vagas e das matrículas efetivas.

No Centro de Artes, dentre os custos apurados, na Direção Administrativa do Centro, o gasto com pessoal apresentou o valor de R\$ 1.200.853,03; a contratação de serviços para operacionalização da administração $\mathrm{R} \$ 962.955,61$; serviços e materiais administrativos no valor de R\$ 154.978,39; encargos com estagiários R $\$ 5.537,80$ e serviços de telecomunicações R \$ 15.350,41; totalizando R $\$ 2.339 .675,24$. Para o cálculo do gasto com pessoal, foi utilizada a planilha gerencial de lotação de servidor por departamento/direção da Coordenadoria de Recursos Humanos do CEART, acrescentando nesta planilha o valor do salário bruto de cada servidor, multiplicando-se pelo fator 13,33, a fim de considerar os 12 meses, $1 / 3$ de férias e o $13^{\circ}$ salário.

Os valores de contratação de serviços para a operacionalização da administração, serviços e materiais administrativos, encargos com estagiários e serviços de telecomunicações foram obtidos do relatório fornecido pelo sistema SIGEOF, sendo sempre observado se havia algum custo direto compreendido neste relatório e, em havendo, o valor foi descontado para fins de alocação como custo direto nos departamentos, pós-graduações e/ou demais direções.

Na Direção de Ensino, os custos diretos foram: passagens R\$ 1.556,36; pessoa física $\mathrm{R} \$ 1.270,00$; pessoa jurídica $\mathrm{R} \$ 1.439,90$; folha de pagamento dos técnicos vinculados à Direção de Ensino R\$ 539.058,80; e função do Diretor de Ensino R\$ 37.275,88; totalizando o custo direto da Direção de Ensino em R \$ 580.521,04. Como possui uma relação direta com o ensino, para distribuição do custo desta direção, utilizou-se o número de matrículas de alunos de graduação existentes no ano de 2013 em cada departamento e se distribuiu o custo proporcionalmente ao departamento.

Os projetos de ensino (PRAPEG) foram analisados de acordo com o professor responsável por eles, alocando o custo executado do projeto ao departamento. Em 2013, foram executados R $\$ 48.382,02$ referentes ao Edital PRAPEG. Deste valor, 16,30\% foi 
alocado ao departamento de Artes Visuais, 17,92\% ao departamento de Design, 20,67\% ao departamento de Artes Cênicas; 26,09\% ao departamento de Moda; e 38,03\% ao departamento de Música.

O salário dos diretores de ensino, pesquisa e pós-graduação e extensão foram alocados aos departamentos e/ou pós-graduação a que estes docentes estão vinculados, devido à continuidade das atividades que os diretores possuem, mesmo no cargo de direção, com projetos de ensino, pesquisa e pós-graduação e extensão, ministração de disciplinas na graduação e/ou pós-graduação, ou seja, eles continuam vinculados às atividades dos departamentos e/ou pós-graduação. Assim, foi alocado ao custo direto das direções apenas o valor correspondente à função de confiança do respectivo diretor.

Os custos diretos identificados na Direção de Pesquisa e Pós-graduação, segundo as planilhas gerenciais, foram: diárias $\mathrm{R} \$ 210,00$; pessoa física $\mathrm{R} \$ 1.200,00$; pessoa jurídica $\mathrm{R} \$$ 500,50; passagens do edital Prodip (Programa de apoio à divulgação de produção intelectual) R\$ 9.984,02; diárias do edital Prodip R\$ 4.915,13; folha de pagamento dos técnicos de apoio R \$ 285.773,07; e função de confiança do Diretor de Pesquisa e Pós-graduação R \$ 37.275,88, totalizando o custo da Direção de Pesquisa e Pós-graduação R \$ 399.858,60. Assim, os custos diretos da Direção de Pesquisa e Pós-Graduação foram rateados aos Departamentos com o valor proporcional ao número de professores efetivos vinculados, por entender que a Direção de Pesquisa e Pós-Graduação está à disposição de todos os docentes efetivos que queiram realizar pesquisas.

A partir de 2013, os projetos de pesquisa estão sendo disponibilizados diretamente na conta do professor pesquisador, devido ao convênio realizado entre a Universidade e a FAPESC. Portanto, este custo não foi tratado no objeto desta pesquisa. As bolsas de iniciação científica e monitoria estão incluídas no custo da Reitoria, devido ao empenho unificado deste custo a todos os Centros de Ensino da UDESC.

Os custos diretos identificados nas planilhas gerenciais do CEART na Direção de Extensão foram: passagens no valor de $\mathrm{R} \$ 1.837,04$; diárias $\mathrm{R} \$ 1.569,00$; pessoa física $\mathrm{R} \$$ 500,00; pessoa jurídica $\mathrm{R} \$ 1.439,90$; folha de pagamento com os técnicos $\mathrm{R} \$ 291.355,85$; e função de confiança do Diretor de Extensão R\$ 37.275,88; totalizando os custos diretos da Direção de Extensão em R\$ 333.977,67. Para distribuição do custo da Direção de Extensão, tomou-se como indicador o número de professores efetivos de cada departamento, por 
entender que a Direção de Extensão está à disposição de todos os docentes efetivos que queiram realizar extensão, assim como a Direção de Pesquisa e Pós-Graduação.

Os recursos destinados aos projetos de extensão, via Edital PAEX, foram identificados pelos professores dos departamentos ao qual o projeto de extensão está vinculado, para distribuição do custo relacionado ao projeto no respectivo departamento. Assim, de um total de R\$ 138.873,76 foi alocado: ao departamento de Design 3,82\%; ao de Artes Visuais 7,40\%; ao de Artes Cênicas 28,15\%; ao de Música 28,92\% e, ao departamento de Moda, 31,71\%.

As entidades públicas são consideradas organizações sem fins lucrativos. Sua remuneração não é devido aos serviços que prestam, ou seja, não vendem serviços. Portanto, as organizações públicas não possuem despesas, pois elas são gastos ligados à obtenção de receitas. Partindo desse conceito, todos os gastos podem ser considerados como custos (MAUSS; SOUZA, 2008). Neste sentido, utilizou-se o método de Custeio por Absorção.

$\mathrm{O}$ custo da folha de pagamento dos docentes vinculados aos Departamentos foi calculado com base na resolução que estabelece normas para a ocupação docente na Universidade. Diante da resolução, percebeu-se que os docentes vinculados à graduação e pós-graduação utilizam $1 / 3$ da carga horária na graduação e $2 / 3$ na pós-graduação. Há docentes que só estão vinculados à graduação, ou seja, utilizam 100\% da carga horária na graduação. E há aqueles que estão ligados a mais de um programa de pós-graduação, utilizando-se, assim, a proporção de 1/3 para cada programa de pós-graduação. Assim, a folha de pagamento do Departamento de Artes Cênicas totalizou R\$ 1.995.229,42 dos docentes e $\mathrm{R} \$ 170.546,02$ dos técnicos. Os custos diretos realizados nas rubricas passagens, diárias, pessoa física e pessoa jurídica foram de $\mathrm{R} \$ 23.962,68$ para o departamento. Os custos diretos do Departamento de Artes Cênicas totalizaram R $\$ 2.238 .827,92$.

Quanto aos custos indiretos alocados ao departamento, foram rateados os custos da operacionalização da administração do CEART e os custos das direções (geral, ensino, extensão, pesquisa e pós-graduação e administração), de acordo com cada indicador préestabelecido. Estes custos foram alocados, primeiramente, aos cinco departamentos e, posteriormente, o percentual correspondente à graduação e à pós-graduação, utilizando-se como indicador a quantidade de docentes respectivamente. Foram alocados $\mathrm{R} \$ 534.018,84$.

Além disso, foi rateado entre os departamentos e programas de pós-graduação, o custo da Reitoria em 2013. Para o departamento de Artes Cênicas foi alocado o valor de R\$ 486.125,56; utilizado, como indicador, a quantidade de servidores que cada departamento 
possui. O custo total do Departamento de Artes Cênicas foi de R\$ 3.258.972,32. Assim, dividindo o valor total do Departamento pelo número de vagas oferecidas e, posteriormente, pela média das matrículas efetivas no Departamento de Artes Cênicas, em 2013, (conforme Tabela 1) tem-se o custo da vaga do aluno de graduação de Artes Cênicas no valor de $\mathrm{R} \$$ 24.140.54/ano e o custo do aluno matriculado no valor de $\mathrm{R} \$ 19.456,55 /$ ano.

Vinculado ao departamento de Artes Cênicas, há o Programa de Pós-Graduação em Teatro (PPGT). Este programa possui dois cursos com níveis de formação hierarquizados, que são o Mestrado e o Doutorado. O curso de Mestrado foi implantado, em 2002, e o de Doutorado em 2009. A folha de pagamento do Programa de Pós-graduação em Teatro totalizou $\mathrm{R} \$ 1.798 .247,04$ dos docentes e $\mathrm{R} \$ 109.527,54$ dos técnicos. Os custos diretos realizados nas rubricas passagens, diárias, pessoa física e pessoa jurídica foram $\mathrm{R} \$ 16.109,34$.

A UDESC realiza convênios com entidades para recebimento de recursos externos. No caso da pós-graduação, vem sendo realizado o convênio com a CAPES (Programa de Apoio à Pós-graduação) visando o fomento ao crescimento e à consolidação dos cursos oferecidos pela instituição. Em 2013, o programa de pós-graduação em teatro executou R $\$ 124.804,36$. Assim, adicionando o custeio direto com recursos PROAP, custeio direto com recursos do Centro e folhas de pagamento (docentes e técnicos), os custos diretos do Programa de PósGraduação em Teatro totalizaram R \$2.048.688,28.

Quanto aos custos indiretos alocados ao Programa, foram rateados os de operacionalização da administração do CEART e os custos das direções (geral, ensino, extensão, pesquisa e pós-graduação e administração), de acordo com cada indicador préestabelecido. Estes custos foram rateados, primeiramente, entre os cinco departamentos e, posteriormente, os valores respectivos aos programas de pós-graduação, conforme o indicador quantitade de docentes do programa x quantidade de docentes no Departamento. Com este critério, o valor alocado referente aos custos indiretos do CEART foi de R \$ 207.673,99.

Além disso, foi utilizado o mesmo critério e indicador para o rateio do custo da Reitoria em 2013. Assim, para o Programa de Pós-Graduação em Teatro foi alocado o valor de $\mathrm{R} \$ 189.059,33$ como custo indireto da Reitoria. Portanto, o custo total do Programa em Teatro foi de R $\$ 2.445 .421,60$. Assim, o custo da vaga para este Programa no ano de 2013 foi de $\mathrm{R} \$ 30.567,77 /$ ano e o custo do aluno matriculado de $\mathrm{R} \$ 38.816,22 /$ ano.

$\mathrm{O}$ custo calculado com a folha de pagamento dos docentes vinculados ao Departamento de Artes Visuais totalizou R\$ 3.019.564,83 e dos técnicos R \$225.855,39. Os 
custos diretos das rubricas passagens, diárias, pessoa física, pessoa jurídica, material de consumo e convênio interno foram de $\mathrm{R} \$ 16.636,68$ para o departamento. Os custos diretos totalizaram R\$3.280.222,98. Quanto aos custos indiretos alocados ao departamento, foram rateados os da operacionalização da administração do CEART e os custos das direções (geral, ensino, extensão, pesquisa e pós-graduação e administração), de acordo com cada indicador pré-estabelecido e critério mencionado no Departamento anterior. Assim, os custos indiretos do CEART alocados foram de $\mathrm{R} \$ 650.813,75$. Além disso, foi incluído o valor de $\mathrm{R} \$$ 648.203,41, referente ao rateio do custo da Reitoria em 2013. O custo total do Departamento de Artes Visuais foi de $\mathrm{R} \$ 4.579 .240,14$. Portanto, o custo da vaga para este departamento no ano de 2013 foi de $\mathrm{R} \$ 23.850,21 /$ ano e o custo do aluno matriculado de $\mathrm{R} \$ 20.534,71 /$ ano.

Vinculado ao departamento de Artes Visuais, há o Programa de Pós-Graduação em Artes Visuais (PPGAV), que também detém dois cursos: Mestrado e Doutorado. O curso de Mestrado foi implantado, em 2005, e o de Doutorado em 2013. A proposta do Programa é dar continuidade e promover novos avanços às pesquisas em arte no campo da produção, significação e do ensino. O custo calculado com a folha de pagamento dos docentes vinculados ao Programa de Pós-Graduação em Artes Visuais totalizou R\$ 1.131.428,45 e o dos técnicos R\$244.212,4. Os custos diretos realizados nas rubricas passagens, diárias, pessoa física e pessoa jurídica foram de $\mathrm{R} \$ \mathrm{R} \$$ 9.514,29 no programa de pós-graduação.

Assim como a Pós-Graduação em Teatro, os cursos de Pós-Graduação em Artes Visuais também recebem recursos externos oriundos do convênio com a CAPES. Em 2013, este Programa utilizou R \$ 38.079,21 nas rubricas passagens, diárias, pessoa jurídica e auxílio financeiro a estudantes. Com este recurso, os custos diretos do Programa totalizaram R\$ 1.423.234,53. Quanto aos custos indiretos alocados à Pós-Graduação em Artes Visuais, foi alocado o valor devido ao posterior rateaio deste custo ao Departamento de Artes Visuais, de acordo com o critério e o indicador pré-estabelecido. Desse modo, foram alocados $\mathrm{R} \$$ 162.703,44 referente ao custo indireto do CEART. Além disso, foi incluído o valor de R\$ 162.050,85, referente ao rateio do custo da Reitoria em 2013. O custo total do Programa de Pós-Graduação em Artes Visuais foi de R\$ 1.747.988,64. Assim, o custo da vaga para este Programa no ano de 2013 foi de R\$ 37.999,65/ano e o custo do aluno nele matriculado o mesmo valor.

O custo calculado com a folha de pagamento dos docentes vinculados ao Departamento de Design totalizou R $\$ 2.028 .846,04$ e dos técnicos R $\$ 102.875,21$. Os custos 
diretos foram de $\mathrm{R} \$ 1.197,00$ na rubrica diárias para o departamento. Portanto, os custos diretos totalizaram $\mathrm{R}$ \$ 2.146.900,58. Quanto aos custos indiretos da operacionalização da administração do CEART e os custos das direções (geral, ensino, extensão, pesquisa e pósgraduação e administração), foram alocados R\$ 607.246,19, de acordo com o critério e indicador para de rateio. Além disso, foi incluído o valor de R\$474.116,17, referente ao rateio do custo da Reitoria em 2013. O custo total do Departamento de Design foi de R\$ 3.228.262,94. Portanto, o custo da vaga para este departamento no ano de 2013 foi de R\$ $23.850,21 /$ ano e o custo do aluno matriculado de $\mathrm{R} \$ 20.534,71 /$ ano.

Vinculado ao departamento de Design, há o Programa de Pós-Graduação em Design (PPGD) implantado em 2011 e que possui o curso de mestrado acadêmico. O custo calculado com a folha de pagamento dos docentes vinculados ao Programa de Pós-Graduação em Design totalizou $\mathrm{R} \$ 653.624,73$ e dos técnicos $\mathrm{R} \$ 68.034,45$. Os custos diretos realizados com recurso do Centro foram de $\mathrm{R} \$ 6.380,91$ nas rubricas passagens, diárias e pessoa fisica.

O curso de pós-graduação em Design também recebe recurso externo oriundo do convênio com a CAPES. Em 2013, este programa de pós-graduação utilizou R $\$ 30.895,96$ nas rubricas passagens, diárias, pessoa jurídica e auxílio financeiro a estudantes. Desse modo, os custos diretos deste Programa totalizaram R\$ 758.936,05. Quanto aos custos indiretos alocados ao Programa, estão os custos indiretos do CEART, cujo valor alocado foi de R\$ 127.841,30. Além disso, foi incluído o valor de R\$99.813,93, referente ao rateio do custo da Reitoria em 2013. Por fim, o custo total do Programa de Pós-Graduação em Design foi de R\$ 986.521,28. Portanto, o custo da vaga para este Programa no ano de 2013 foi de R\$ $49.329,26 /$ ano e o custo do aluno matriculado de $\mathrm{R} \$ 53.329,26 /$ ano.

O custo calculado com a folha de pagamento dos docentes vinculados ao Departamento de Moda totalizou R\$ 2.375.995,05 e dos técnicos R\$ 113.290,74. Os custos diretos do departamento foram de $\mathrm{R} \$ 18.816,88$ nas rubricas passagens, diárias e pessoa jurídica. Os custos diretos totalizaram $\mathrm{R} \$ 2.564 .760,02$. Nos custos indiretos alocados ao departamento estão os custos da operacionalização da administração do CEART e os custos das direções (geral, ensino, extensão, pesquisa e pós-graduação e administração), resultando em $\mathrm{R} \$ 694.927,41$. Além disso, foi incluído o valor de $\mathrm{R} \$ 472.648,32$, referente ao rateio do custo da Reitoria em 2013. O custo total do Departamento de Moda foi de R\$ 3.732.335,75. Assim, o custo da vaga para este departamento no ano de 2013 foi de R\$19.643,87/ano e o custo do aluno matriculado de R\$17.943,92/ano. 
O Departamento de música oferece os cursos de Licenciatura e Bacharelado. No curso de Bacharelado em Música há as opções em Piano, Violão, Violino, Viola e Violoncelo. O custo calculado com a folha de pagamento dos docentes vinculados ao Departamento de Música totalizou R $\$ 2.783 .789,79$ e dos técnicos R\$123.960,34. Os custos diretos realizados foram de R \$ 21.593,57 nas rubricas passagens, diárias, pessoa física e pessoa jurídica para o departamento. Os custos diretos totalizaram $\mathrm{R} \$ 2.987 .903,92$.

Quanto aos custos indiretos alocados ao departamento, estão os custos da operacionalização da administração do CEART e os das direções (geral, ensino, extensão, pesquisa e pós-graduação e administração), de acordo com o indicador para o rateio. Foram alocados R\$713.142,36. Ainda, há o valor de $\mathrm{R} \$ 726.790,57$, referente ao rateio do custo da Reitoria em 2013. O custo total do Departamento de Música foi de R\$4.427.836,85. Assim, o custo da vaga para este departamento no ano de 2013 foi de $\mathrm{R} \$ 23.552,32 /$ ano e o custo do aluno matriculado de $\mathrm{R} \$ 22.476,33$ /ano.

Vinculado ao departamento de Música, há o Programa de Pós-Graduação em Música (PPGMUS). O custo calculado com a folha de pagamento dos docentes vinculados ao Programa de Pós-Graduação em Música totalizou R\$ 1.090.251,46 e dos técnicos R\$ 71.747,79. Os custos diretos realizados com recurso do Centro foram nas rubricas passagens, foram diárias e pessoa jurídica no valor de $\mathrm{R} \$ 7.312,35$ no programa de pós-graduação.

Assim como nas demais pós-graduações, o curso de Pós-Graduação em Música também recebe recurso externo oriundo do convênio com a CAPES. Em 2013, este programa utilizou R \$ 51.573,44 nas rubricas passagens, diárias, pessoa jurídica e auxílio financeiro a estudantes. Portanto, os custos diretos deste Programa totalizaram R\$1.220.885,04. Quanto aos custos indiretos alocados ao Programa de Pós-Graduação em Música, os custos indiretos do CEART foram de R\$115.022,96. Ainda, há o valor de R \$117.224,29, referente ao rateio do custo da Reitoria em 2013. Assim, o custo total do Programa de Pós-Graduação em Música foi de R\$1.453.132,29. Por fim, o custo da vaga para este Programa no ano de 2013 foi de $\mathrm{R} \$ 24.218,87 /$ ano e o custo da vaga no ano pesquisado de $\mathrm{R} \$ 44.711,76 /$ ano.

\section{CONSIDERAÇÕES FINAIS}

Nesta pesquisa objetivou-se determinar o cálculo de custo por vaga e matrícula efetiva em uma Universidade Pública, especificamente, no Centro de Artes da Universidade do Estado de Santa Catarina. A estruturação de uma proposta para o cálculo do custo por vaga 
em curso de graduação e de pós-graduação em universidade pública pode ter seu desenvolvimento e concepção, de forma preliminar, com base em algumas metodologias de custeio. Privilegiou-se, aqui, o desenvolvimento do trabalho com base no método do Custeio por Absorção, devido à inexistência de um sistema de custos na Universidade objeto do estudo.

Em relação ao cálculo do custo de uma vaga em curso de graduação e de uma vaga em curso pós-graduação em universidade pública, é importante ressalvar que a estrutura departamental da Universidade do Estado de Santa Catarina, objeto deste estudo de caso, possibilita que, num mesmo departamento haja mais de um curso de graduação associado.

Assim, o custo por vaga de cada Programa de Pós-Graduação neste estudo de caso importou em uma média para o Centro de Artes da Universidade do Estado de Santa Catarina em R\$ 35.528,99/ano e o custo médio de cada estudante matriculado em R\$ 43.714,25/ano. Isto importa dizer que, na média, o custo por vaga de graduação, neste estudo de caso, resultou em uma média de $\mathrm{R} \$ 23.200,72 /$ ano e o custo médio de matrícula efetiva em $\mathrm{R} \$$ 19.679,25/ano. O custo de uma vaga em uma pós-graduação no Centro de Artes importa em R \$ 2.960,75/mês. Se consideradas as matrículas existentes, este custo aumenta consideravelmente, importando em 3.642,85/mês.

Entende-se que um dos papéis da Universidade é promover a cultura, a qual pode ser promovida pelas artes cênicas, visuais e música, seja no campo do ensino, da pesquisa e da extensão. O Centro de Artes vem desempenhando seu papel na sociedade há 29 anos e, se comparada a média dos valores calculados das vagas dos cursos oferecidos com a pesquisa realizada por The Organisation for Economic Co-operation and Development (OECD), transformando o valor médio da vaga anual em dólares, este valor está abaixo do valor da despesa anual por estudante do ensino superior no Brasil, que foi U\$ 13.137 e, também, está abaixo da média da OECD, a qual foi U\$ 13.528 (OECD, 2013). Considerando a taxa de câmbio publicada pela Receita Federal do Brasil para fins de elaboração de balanço relativo ao mês de dezembro de 2013, o valor médio da vaga em dólares é 9.912,36/ano no Centro de Artes da Universidade do Estado de Santa Catarina.

\section{REFERÊNCIAS}

BRASIL. Lei $n^{0}$ 13.005, de 25 de junho de 2014. Aprova o Plano Nacional de Educação PNE e dá outras providências. Diário Oficial da República Federativa do Brasil, Brasília, 
DF, 25 jun. 2014. Disponível em:< http://www.planalto.gov.br/CCIVIL_03/_Ato20112014/2014/Lei/L13005.htm>. Acesso em: 30 ago 2014.

BRASIL. Lei Complementar $\mathbf{n}^{\mathbf{0}} \mathbf{1 0 1}$, de 04 de maio de 2000. Estabelece normas de finanças públicas voltadas para a responsabilidade na gestão físcal e dá outras providências. Disponível em: <http://www.planalto.gov.br/ccivil_03/leis/lcp/lcp101.htm>. Acesso em: 30 ago 2014.

BONACIM, Carlos Alberto Grespan; ARAUJO, Adriana Maria Procópio de. Gestão de custos aplicada a hospitais universitários públicos: a experiência do Hospital das Clínicas da Faculdade de Medicina de Ribeirão Preto da USP. Revista de Administração Pública, v. 44, n. 4, p. 903-931, 2010.

CONSELHO FEDERAL DE CONTABILIDADE. Resolução CFC No. 1.129/08, de 21 de novembro de 2008. Aprova a NBC T 16.2 - Patrimônio e Sistemas Contábeis. Disponível em: $<$ http://www3.tesouro.gov.br/contabilidade_governamental/download/RES_CFC11292008_N BC_T162_Patrimonio_Sistemas_Contabeis.pdf >. Acesso em: 16 out. 2014.

CONSELHO FEDERAL DE CONTABILIDADE. Resolução CFC N 1.366, de 25 de novembro de 2011. Aprova a NBC T 16.11 - Sistema de Informação de Custos do Setor Público. Disponível em: <http://www.normaslegais.com.br/legislacao/resolucao-cfc-13662011.htm> Acesso em: 16 out. 2014.

CONSELHO FEDERAL DE CONTABILIDADE. Normas Internacionais de Contabilidade para o Setor Público. Ed. 2010. Disponível em:

$<$ http://portalcfc.org.br/wordpress/wp-content/uploads/2013/01/ipsas2010_web.pdf $>$. Acesso em: 16 out. 2014.

CRUZ, Flávio da, PLATT NETO, Orion Augusto. Contabilidade de custos para entidades estatais: metodologias e casos simulados. Belo Horizonte: Fórum, 2007.

HEUSI, Aline Cristina da Silva; RAUPP, Fabiano Maury; MORAES, Mário César Barreto. Utilização de Sistemas Custos em Universidades Públicas Federais e Estaduais Brasileiras.

Revista Espacios, v. 35, n. 4, p. 4, 2014.

LEONE, George Sebastião Guerra. Custos: planejamento, implantação e controle. São Paulo: Atlas, 2009.

MAHER, Michael. Contabilidade de custos: criando valor para a administração. São Paulo: Atlas, 2001.

MAGALHÃES, Elizete Aparecida; SILVEIRA, Suely de Fátima Ramos; ABRANTES, Luiz Antônio; FERREIRA, Marco Aurélio Marques; WAKIM, Vasconcelos Reis. Custo do ensino de graduação em instituições federais de ensino superior: o caso da Universidade Federal de Viçosa. Revista de Administração Pública, v. 44, n. 3, p. 637-666, 2010.

MARTINS, Eliseu. Contabilidade de Custos. São Paulo: Atlas, 2008. 
MARTINS, Eliseu, ROCHA, Welington. Métodos de custeio comparados: custos e margens analisados sob diferentes perspectivas. São Paulo: Atlas, 2010.

MAUSS, César Volnei; SOUZA, Marco Antonio de. Gestão de custos aplicada ao setor público: modelo para mensuração e análise de eficiência e eficácia governamental. São Paulo: Atlas, 2008.

NAKAGAWA, Masayuki. ABC: custeio baseado em atividades. São Paulo: Atlas, 2001.

ORGANISATION FOR ECONOMIC CO-OPERATION AND DEVELOPMENT (OECD). Education at a Glance 2013: Indicadores da OCDE. Country Notes: Brasil. Disponível em: $<$ http://www.oecd.org/edu/Brazil_EAG2013\%20Country\%20Note\%20(PORT).pdf $>$. Acesso em: 30 set. 2014.

PORTON, Rosimere Alves de Bona Porton; BEUREN, Ilse Maria. Formulação de hipóteses e caracterização de variáveis em pesquisa contábil. In: BEUREN, Ilse Maria (org.). Como elaborar trabalhos monográficos em contabilidade: teoria e prática. 2. ed. São Paulo: Atlas, 2004. pp. 98-116.

RAUPP, Fabiano Maury; BEUREN, Ilse Maria. Metodologia da pesquisa aplicável às ciências sociais. In: BEUREN, Ilse Maria (org.). Como elaborar trabalhos monográficos em contabilidade: teoria e prática. 2. ed. São Paulo: Atlas, 2004. pp. 76-97.

RIBEIRO FILHO, José Francisco. Elementos de contabilidade gerencial para hospitais públicos: reflexões em torno de um novo Paradigma. In: CONGRESSO BRASILEIRO DE CUSTOS, 9., 2002, São Paulo. Anais... São Leopoldo, ABCustos, 2002.

SILVA, Lino Martins da. Problemas para o desenho e implantação de um sistema de custos na administração pública, o método Activity Based Costing (ABC). In: CONGRESSO INTERNACIONAL DE CUSTOS, 10., 2007, Lyon, França. Anais... Lyon, França: Congresso Internacional de Custos, 2007.

SLOMSKI, Valmor. Manual de contabilidade pública: um enfoque na contabilidade municipal. 2. ed. São Paulo: Atlas, 2006. 